\title{
"Si los telegramas no mienten". Origen y circulación de las noticias de la explosión del Maine en la prensa mexicana, febrero $1898^{*}$
}

\author{
Rocio Castellanos Rueda** \\ Ernesto Priani Saiso**** \\ Laura Martinez Dominguez****
}

Recibido el 22 de enero de 2020; aceptado el 9 de mayo de 2020

\section{RESUMEN}

El objetivo de este artículo es estudiar los circuitos de información en la prensa mexicana en torno a la noticia de la explosión del Buque Maine en la Bahía de La Habana el 15 de febrero de 1898. Para ello utilizamos herramientas digitales como identificación de expresiones regulares, KeyWords y NER con el fin de identificar patrones de circulación y temas relevantes en los diarios. Nuestros resultados indican un predominio notable de las noti-

* $\quad$ El presente trabajo se realizó en colaboración con las investigadoras: Laura Angélica López Méndez y Ximena Gutiérrez-Vasques. Todos integrantes del grupo Oceanic Exchanges-México.

** Universidad Nacional Autónoma de México, Ciudad de México, México. Correo electrónico: doroci2011@gmail.com. ORCID: https://orcid.org/0000-0002-3255-592X.

*** Universidad Nacional Autónoma de México, Ciudad de México, México. Correo electrónico: epriani@gmail.com. ORCID: https://orcid.org/0000-0003-2908-0457.

**** Universidad Panamericana, Ciudad de México, México. Correo electrónico: lauramartinezdominguez@gmail.com. 
cias producidas en Estados Unidos, y un dominio de la narrativa sobre el acontecimiento a partir de la información generada por instituciones norteamericanas.

Palabras clave: Prensa, México, Maine, flujos, noticias.

\section{"If the telegrams do not lie". Origin and circulation of the news of the explosion of the Maine in the Mexican press, February 1898}

\section{AbStract}

The objective of this article is to study the information circuits in the Mexican press about the news of the explosion of the Maine Ship in the Bay of Havana on February 15, 1898. For this we use digital tools as identification of regular expressions, KeyWords and NER in order to identify circulation patterns and relevant issues in newspapers. Our results indicate a remarkable predominance of the news produced in the United States, and a dominance of the narrative about the event from the information generated by North American institutions.

Key words: Newspapers, Mexico, Maine, flows, news.

\section{"Se os telegramas não mentem". Origem e circulação das notícias da explosão do Maine na imprensa mexicana, fevereiro de 1898}

\section{RESUMO}

O objetivo deste artigo é estudar os circuitos informação e as linhas editoriais na imprensa mexicana sobre as notícias da explosão do navio Maine na baía de Havana em 15 de fevereiro de 1898. Para isso, usamos ferramentas digitais como identificação de expressões regulares, KeyWords e NER, a fim de identificar padrões de circulação e questões relevantes nos jornais. Nossos resultados indicam um notável predomínio das notícias produzidas nos Estados Unidos, e um domínio da narrativa sobre o evento a partir das informações geradas pelas instituições norte-americanas.

Palavras chave: Jornais, Mexico, Maine, flui, notícias. 
$\mathrm{E}$ n el mes de mayo de 1898, cuando en Cuba se confrontaban España y Estados Unidos, el poeta nicaragüense Rubén Darío publicó en El Tiempo de Buenos Aires el ensayo “El Triunfo de Calibán”, para fijar su postura ante la guerra: "No, no puedo, no quiero estar de parte de esos búfalos de dientes de plata. Son enemigos míos, son los aborrecedores de la sangre latina, son los Bárbaros. Así se estremece hoy todo noble corazón, así protesta todo digno hombre que algo conserve de la leche de la Loba”. ${ }^{1}$

Darío miró la pugna entre españoles y estadounidenses como una contienda entre civilización y barbarie, entre hidalgos y “comedores de dólares”, entre la España de Cervantes, el Cid e Isabel, y "el país de Brobdingnag: tienen el Niágara, el puente de Brooklyn, la estatua de la Libertad, los cubos de veinte pisos, el cañón de dinamita, Vanderbilt, Gould, sus diarios y sus patas". ${ }^{2}$ No debe sorprender que Darío haga mención de los diarios del lado de la barbarie. Si hay un lugar al que se trasladan las tensiones alrededor de los acontecimientos en Cuba y, en especial, la del estallido del buque Maine en el puerto de La Habana el 15 de febrero de 1898 es precisamente al de los diarios. Es en ellos donde se juega, por ejemplo, si el estallido fue producto de un accidente o de un atentado, para ganar la opinión pública y, por qué no, justificar la guerra.

Precisamente, en este artículo nos interesa indagar cómo, a raíz del estallido del Maine, la circulación de las noticias a finales del siglo XIX destacó ciertas fuentes sobre otras, a las que volvía dominantes, sin importar la lengua o el lugar donde se publicaron las noticias. Para estudiar este fenómeno seleccionamos un espacio específico donde analizar la difusión de la noticia: los periódicos de la ciudad de México resguardados en la Hemeroteca Nacional Digital de México (en adelante HNDM). ${ }^{3}$

Las razones de esta elección son varias. En primer lugar, esta investigación se enmarca dentro del proyecto Intercambios Oceánicos: Trazando redes de información global en repositorios de periódicos históricos, 1840$1914,{ }^{4}$ donde se busca rastrear e identificar la circulación de textos, así como

\footnotetext{
Darío, “El triunfo de Calibán”, p. 451.

Ídem.

Disponible en www.hndm.unam.mx/

Intercambios Oceánicos es un proyecto internacional que reúne a investigadores de nueve universidades y con financiamiento de Conacyt (FONCICYT 274861) a través de la convocatoria Transatlantic Partnership for Social Sciences and Humanities 2016 Digging Into Data Challenge. Al tratarse de un proyecto muy amplio y de largo alcance, contempla diversos objetivos. Los tres más relevantes en este caso son: 1 ) crear una base de datos de periódicos decimonónicos con la contribución de 8 hemerotecas digitales nacionales, entre las que se encuentra la Hemeroteca Digital Nacional de México. 2) Utilizar herramientas digitales de análisis lingüístico para estudiar el flujo información noticiosa a partir del corpus creados y 3) Analizar casos concretos de flujos de noticias a partir de subcopus creados con
} 
la reutilización de las publicaciones en los diarios del siglo XIX, mediante el uso de herramientas computacionales en un amplio corpus digital hemerográfico formado a partir de diversas hemerotecas nacionales. ${ }^{5}$ En segundo lugar, uno de los objetivos del proyecto fue estudiar eventos que tuvieran una amplia repercusión informativa mundial, para observar de manera concreta, en episodios localizados en diversas latitudes y en distintos momentos, cómo circulaban y reutilizaban las noticias. En tercer lugar, uno de estos eventos fue el caso de la explosión del buque de guerra Maine, por tratarse de un suceso claramente identificable y datable, por la magnitud de su difusión en la prensa y por la significación política que la guerra entre España y Estados Unidos tuvo en la consolidación de este último país como potencia emergente frente a los grandes imperios europeos. En cuarto lugar, dentro del proyecto se ha desarrollado un estudio de la difusión del evento en la prensa de distintos países, como parte de los resultados de ese análisis nos detuvimos en el caso de los diarios publicados en la ciudad de México porque su conformación en el momento ofrece una oportunidad única.

En la última década del siglo XIX, la prensa de la ciudad de México estaba conformada por una gama de periódicos que no sólo representaba los intereses de diversos grupos nacionales, sino también los de las comunidades extranjeras radicadas en México, notablemente la española y la norteamericana. Dada la cercanía geográfica con Cuba y Estados Unidos, y la relación singular que se mantenía con España, la prensa mexicana resultó un espacio extraordinario para indagar de dónde provenían las noticias, cómo llegaban aquí, quiénes las reproducían, y cómo fueron tratadas en este escenario de crisis diplomática e informativa.

El estudio y debate acerca de la emancipación cubana en los diarios mexicanos ya ha sido objeto de estudio, por lo que conocemos aspectos fundamentales sobre su contenido y desarrollo, además de otros rasgos como el peso diplomático y las identidades de los grupos políticos detrás de los diarios. Por este motivo, podemos afirmar que la prensa mexicana presentó rasgos singulares, pues ahí polemizaron los periódicos de las

ese fin, y utilizando las herramientas mencionadas. El caso del estallido del acorazado Maine en la bahía de La Habana fue uno de los seis casos de estudio elegidos por el grupo internacional para, mediante la aplicación de las herramientas digitales, conocer cómo se producían los intercambios informativos en la segunda mitad del siglo XIX. https://intercambiosoceanicos.iib.unam.mx/

5 Las hemerotecas participantes fueron: The Times Digital Archive, Europeana Newspapers, especialmente las colecciones de: Austrian National Library, Berlin State Library, Hamburg State and University Library, Dr. Friedrich Tessman Library South-Tyrol, además The Digital Collection of the National Library of Finland, British Newspaper Archive The British Library's Digitised Newspaper Collections, Library of Congress Chronicling America Project y la Hemeroteca Nacional Digital de México. 
comunidades estadounidense, española y de las propias facciones nacionales. ${ }^{6}$ Ninguno de estos estudios, sin embargo, se han detenido en el evento político, paralelo a la guerra: la cobertura de la explosión del Maine, por lo que su examen permite aportar a los trabajos ya hechos. Además, los estudios no se han hecho aplicando herramientas computacionales sobre un corpus hemerográfico digital, por lo que el enfoque seguido aquí ofrecerá nuevos elementos para entender la cobertura a estos eventos de la prensa en la ciudad de México.

En concreto, nuestro objetivo con el análisis de la cobertura del caso Maine en la prensa de la ciudad de México es conocer y estudiar las fuentes y circuitos de información, pues nos interesa estudiar el origen de la información en los distintos medios para valorar los flujos de información mediante el rastreo del punto geográfico donde se desplegó la cobertura del evento. De esta manera, podemos reconocer cómo una parte de la prensa mexicana cubrió e interpretó la noticia de la explosión del Maine en el contexto de la guerra de independencia cubana.

Para llevar a cabo este plan, en el presente artículo apuntaremos, en primer lugar, algunas cuestiones sobre la elaboración de nuestro corpus de investigación; en segundo lugar, presentaremos un breve panorama de la prensa de la ciudad de México con el propósito de señalar los grupos políticos que siguieron la cuestión de la insurrección cubana; en tercer lugar, expondremos los lineamientos de la cobertura de la noticia de la explosión del Maine para abordar las fuentes de información y la circulación de la nota y; en cuarto y último lugar, analizaremos el tono y el ritmo del contenido de la noticia en los periódicos mexicanos.

Nuestros resultados, como se verá en el desarrollo del artículo, muestran cómo la información generada desde Estados Unidos es dominante en la cobertura de la prensa de la ciudad de México, incluso sobre la información proveniente de La Habana y, por supuesto, de España, debido, entre otras cosas, a las conexiones telegráficas y el lugar, en ellas, que ocupan los países involucrados, a los intereses políticos y al control de la información que ejercieron las autoridades norteamericanas.

6 Bobadilla González, “La opinión pública en México”; Bobadilla González, “1898, Guerra de tinta suelta”, pp. 127-154; Bobadilla González, La Revolución cubana; Lizardi Pollock, “Imaginar el 98”, pp. 321-341; Muñoz Mata, “México ante la independencia cubana”, pp. 19-32; Pérez Vejo, “La guerra hispano-estadounidense”, pp. 271-308 y Rojas, "La política mexicana”, pp. 783-805. Los autores de este artículo reconocemos la generosidad de Leticia Bobadilla González por proporcionarnos su valioso libro. 


\section{LA FORMACIÓN DEL CORPUS DE NOTICIAS DE LA EXPLOSIÓN DEL MAINE}

Para elaborar el corpus de trabajo de las notas publicadas en los periódicos de la ciudad de México se comenzó por hacer un rastreo de las noticias sobre la explosión del acorazado Maine entre el 16 y el 22 de febrero de 1898, mediante el descubridor de la HNDM. La elección del período corresponde, en primer lugar, a los días de más álgida confrontación entre Estados Unidos y España, debido a que en ese momento no sólo se produce la explosión, sino que se inicia la investigación sobre las causas del hundimiento. En segundo lugar, procedimos a transcribir todas las notas que se localizaron debido a que el número de noticias no era muy grande y el Optical Character Recognition (en adelante OCR) que se extrajo de las imágenes de la HNDM ofrecía muchas dificultades para trabajar con él. Con ellas conformamos un corpus total de 657 noticias publicadas en 15 distintos periódicos. Sobre este corpus analizamos algunas cuestiones sobre su número, fuentes de información y contenido. Para su examen se emplearon diferentes herramientas digitales que permitieron identificar los lugares, sujetos e instituciones que emitieron las informaciones sobre el Maine, al mismo tiempo que nos facilitaron establecer el desarrollo temático de la cobertura mediática, como se explicará más adelante.

\section{PANORAMA DE LA PRENSA DE LA CIUDAD DE CIUDAD DE MÉXICO A FINALES DEL SIGLO XIX}

Durante la década de 1890 en la ciudad de México se imprimieron alrededor de un centenar de periódicos, lo que significó un crecimiento en la producción respecto a los años anteriores. ${ }^{7}$ Esta etapa se considera como un punto de arranque de la prensa moderna e industrial en México, ${ }^{8}$ debido a que se inauguró el uso de la prensa rotativa, lo que le permitió a El Imparcial (1896-1914) lanzar en solitario 50000 ejemplares en $1900 .{ }^{9}$ Respecto al contenido, si bien los periódicos de talante político dominaron la escena pública mediante incendiarios y polémicos editoriales, también incorporaron los géneros noticioso e informativo, algunos de éstos no tardaron en volcarse hacia el amarillismo y la nota roja. ${ }^{10}$

\footnotetext{
Coudart, "El espejo estrellado”, p. 259.

Lombardo García, De la opinión a la noticia, pp. 12-13; Fernández Fernández, “Claroscuros de un estadunidense en México", p. 108.

9 Coudart, "El espejo estrellado", p. 259.

10 Toussaint Alcaraz, Escenario de la prensa en el Porfiriato, p. 34; Lombardo García, De la opinión a la noticia, p. 12.
} 
Este carácter informativo tuvo lugar gracias al uso de nuevos medios de comunicación y transporte, como el ferrocarril, el barco de vapor, el telégrafo, el teléfono y las agencias de noticias, ya que permitieron una recolección más rápida y con mayor cobertura de los asuntos de interés público a nivel local y mundial. ${ }^{11}$ También, y a pesar de la paulatina modernización de los contenidos de los periódicos mexicanos, sobresale la tradición literaria en sus columnas, como puede constatarse en las copiosas páginas destinadas a la difusión y discusión de los distintos géneros literarios. ${ }^{12}$

Esta prensa capitalina albergó, sin duda, diferentes posturas e intereses que se vieron reflejadas en constantes disputas por dirigir la política y negocios del Porfiriato. Entre los contendientes asiduos al debate encontramos a los diarios más consolidados como: La Patria (1877-1914), El Nacional (1880-1914), El Diario del Hogar (1881-1912), El Hijo del Ahuizote (18851903), El Universal (1888-1901), El Imparcial (1896-1914) y El Popular (1897-1908). Además de las discusiones entre las fuerzas políticas nacionales, los periódicos de la ciudad de México también representaron las voces de algunos grupos, empresas y gobiernos extranjeros. ${ }^{13}$ De hecho, otro rasgo de la prensa capitalina fue la proliferación de periódicos en lengua extranjera que, aunque no era un fenómeno distintivo del período, resaltó por su papel como vocero de algunos reducidos, pero poderosos miembros de las comunidades española, francesa y estadounidense. ${ }^{14}$

A lo largo del siglo XIX, si bien la comunidad española en México era reducida mantuvo su preponderancia y vitalidad de forma constante. ${ }^{15}$ De hecho, la presencia española se distinguió por su cohesión social que atravesó redes familiares y comerciales distribuidas desde los abarroteros hasta lo más selecto de la élite porfirista. ${ }^{16}$ En particular, desde la década de 1860 se aprecia el creciente y notable papel de los editores, periodistas y escritores peninsulares en la prensa mexicana, como Anselmo de la Portilla, Telésforo García, Enrique Olivarría y Ferrari y Fernando Luis J. De Elizalde ${ }^{17}$. En

Toussaint Alcaraz, Escenario de la prensa en el Porfiriato, pp. 57-58; Lombardo García, De la opinión a la noticia, pp. 36,72.

12 Elizalde, El Correo Español, pp. 119-120.

13 De hecho, como apunta Pablo Piccato, numerosos periódicos de la época recibían subsidios por parte de diferentes gobiernos, políticos y empresarios. Piccato, La tiranía de la opinión, pp. 121-123.

14 Coudart, "Periódicos franceses de la ciudad de México”, pp. 103-105; Fernández Fernández, "Claroscuros de un estadunidense en México", pp. 108-109; Elizalde, El Correo Español, pp. 25-41.

15 Elizalde, El Correo Español, p. 35.

16 Rojas, "La política mexicana ante la guerra de independencia de Cuba (1895-1898)”, p. 785; Pérez Vejo, "La guerra hispano-estadounidense”, pp. 274-275.

17 Elizalde, El Correo Español, p. 31. 
consecuencia, la prensa de la comunidad española fue de la más numerosa y afianzada en el país, de entre ella sobresalen: El Español (1851), La Iberia (1867-1876) La Colonia Española (1873-1879), El Pabellón Español (18331890) y El Correo Español (1889-1914). ${ }^{18}$

Por su parte, la comunidad estadounidense, asentada por lo regular en el norte y centro del país, conoció su expansión a partir de la década de 1870, fenómeno que estuvo en concordancia con el inicio de la industrialización mexicana. En concreto, el interés de los estadounidenses acaudalados estuvo ligado en su mayoría a los negocios industriales y financieros. ${ }^{19}$ Por consiguiente, los periódicos capitalinos escritos en inglés promovidos por empresarios o por la embajada norteamericana secundaron con firmeza el galopante imperialismo de los Estados Unidos. Caso especial representó The Mexican Herald (1895-1914), pues además de defender los intereses de las compañías y asociaciones norteamericanas, recibía un subsidio por parte de la administración del presidente Porfirio Díaz, por lo cual también guardaba lealtad al régimen. ${ }^{20}$

\section{LA GUERRA DE INDEPENDENCLA CUBANA ENLA PRENSA DE LA CIUDAD DE MÉXICO}

El proceso de la guerra de independencia cubana entre 1895 y 1898 fue uno de los temas que cubrió la prensa mexicana con notable atención, debido no sólo a la cercanía geográfica de los eventos, sino porque el conflicto tenía una relevancia internacional significativa, puesto que representaría el fin de la presencia del imperio español en América, lo cual, a su vez modificaría el mapa geopolítico y comercial no sólo en torno a Cuba, sino a toda América. ${ }^{21}$

La lucha de independencia cubana generó un amplio debate y movilización política en México, pues desató disputas periodísticas acerca del derecho de insurrección de los pueblos, la vieja idea de anexar la isla al territorio nacional, cuestiones sobre el racismo o las reservas hacia la expansión estadounidense. ${ }^{22} \mathrm{Al}$ mismo tiempo, se formaron clubs y juntas para apoyar o repeler la causa cubana, entre los que destacan los numerosos clubs procu-

18 Pérez Vejo, “La guerra hispano-estadounidense”, p. 275; Elizalde, El Correo Español, p. 37.

19 Knudson, “The Mexican Herald”, pp. 388-389.

20 Fernández Fernández, “Claroscuros de un estadunidense en México”, pp. 108,115.

21 Bobadilla González, La Revolución cubana en la diplomacia, pp. 125-174; Pérez Vejo, “La guerra hispano-estadounidense”, pp. 271-272; Rojas, “Retóricas de la raza”, pp. 602-603.

22 Pérez Vejo, “La guerra hispano-estadounidense”, pp. 294-295, 281. 
banos por un lado, y por otro, asociaciones peninsulares como el Casino Español, la Cámara de Comercio y la Junta Patriótica. ${ }^{23}$

También, como hemos señalado, las comunidades estadounidense y española contaban con algunos periódicos, de ahí que no es de extrañar que la polémica sobre la guerra cubana resultara significativa entre ellos. Sin embargo, el destino de la isla ocupó de manera sobresaliente las páginas de otros diarios capitalinos que tomaron partido para respaldar por lo menos cuatro posturas: a) a favor de los rebeldes cubanos; b) a favor de la causa española; c) a favor de la intervención norteamericana y, d) la promoción de la neutralidad diplomática. ${ }^{24}$ Por tanto, desde sus trincheras, los periódicos de la ciudad de México reportaron a través de diferentes medios, tales como despachos y cables telegráficos, editoriales de corresponsales, además del intercambio entre agencias de noticias sobre las actividades de los rebeldes cubanos.

\section{LA EXPLOSIÓNDEL MAINE Y LA COBERTURA EN LA PRENSA DE LA CIUDAD DE MÉXICO}

La agitación provocada por el levantamiento armado de los cubanos en busca de su independencia de España ocasionó que las relaciones entre Estados Unidos y el gobierno de ultramar se debilitaran, entre otros temas, porque estos últimos conocían el interés de los americanos en la isla, al ser punto estratégico militar y comercial en el Caribe.

Para enero de 1898, las autoridades españolas habían tomado ciertas medidas políticas contra el gobierno norteamericano, una de ellas fue mantener vigente la prohibición del ingreso de naves de guerra en las aguas limítrofes a la isla. A finales de este mes la negociación entre ambas administraciones arrojó un importante cambio en la política binacional, por primera vez desde iniciado el conflicto, se autorizaba el paso de navíos estadounidenses a Cuba. ${ }^{25}$ Es así como el Maine, que estuvo en el puerto de Key West detenido desde hacía días a la espera de una orden para avanzar hacia la isla, recibió luz verde para navegar. En contraprestación, el gobierno norteamericano permitió la llegada del buque Vizcaya al puerto de New York.

El 25 de enero de 1898, el Maine, comandado por el capitán Dwigth Sigsbee, ancló en la bahía de La Habana a unos 200 metros del crucero español Alfonso XIII, en lo que según las autoridades norteamericanas era una

23 Ibíd., p. 272; Bobadilla González, “Opinión pública en México”, pp. 103-104.

24 Lizardi Pollock, “Imaginar el 98”, p. 323; Bobadilla González, “Opinión pública en México”, pp. 117-118; Pérez Vejo, “La guerra hispano-estadounidense”, pp. 272-275.

25 Barón Fernández, La guerra hispano-norteamericana, p. 61. 
visita de rutina que tenía por objetivo el respaldo de sus ciudadanos, ${ }^{26}$ aunque se tenía conocimiento que el buque venía cargado de armamento. De hecho, en los telegramas publicados en los periódicos españoles, se estimaba superior el valor del Maine ${ }^{27}$ a cualquier otra nave en aguas de ambos territorios, se señaló al buque como peligroso por su carga y su potencial bélico: “el "Maine” llevaba una gran cantidad de materiales explosivos en sus bodegas, materiales que estarían dedicados a hacernos la guerra si llegaba el caso, porque no queremos suponer otra cosa peor todavía”. ${ }^{28}$

En esta situación de ánimos caldeados, sobrevino un evento inesperado. A las nueve de la noche con cuarenta minutos del 15 de febrero, el Maine explotó por los aires en una nube de llamaradas y fragmentos, el General Ramón Blanco, ministro de la Guerra cubano emitió en la madrugada del 16 un parte oficial, replicado en varios diarios españoles, ${ }^{29}$ el comunicado afirma: "Tengo el profundo sentimiento de participar a V.E que acaba de volar el crucero Maine, surto en esa bahía, por incidente, indiscutiblemente casual, creyendo sea explosión calderas dinamo”. ${ }^{30}$ El acorazado se partió a la mitad y se hundió a una decena de metros de profundidad. El saldo fue terrible, perdieron la vida más de 260 hombres. $^{31}$

Un día después, la noticia acaparó la completa atención de la prensa norteamericana, la cual venía alentado una intromisión de su país desde tiempo atrás y ahora, dado el nuevo escenario político, exigía una reacción militar contra el enemigo que había provocado la voladura del Maine. ${ }^{32} \mathrm{El}$

26 Sánchez Gavito, La Catástrofe del Maine, p. 8.

27 Descrito por la prensa mexicana así: “El acorazado americano 'Maine' fue construido en 1888, costó 2.500 .000 pesos, su desplazamiento era de 6,682 toneladas, y su velocidad era de 174 nudos por hora; sus dimensiones: eslora 93.4; manga 16.1; máximo calado 66. Tenía dos máquinas verticales de triple expansión; dos hélices, 9,203 caballos de vapor indicado. Montaba cuatro cañones rayados de $25 \mathrm{~cm}$. en dos torres, seis de 15; siete de tiro rápido de seis libras, ocho idem de una libra; cuatro gatlings; cuatro tubos lanza-torpedos, y dos palos militares. Estaba al servicio desde 1896. Lo mandaba el Capitán de la Armada Americana Charles Dwigh-Sigsbee y su dotación era de 450 hombres e inclusive 30 oficiales”. El Universal, ciudad de México, 18 de febrero de 1898. Se conservó la ortografía original en todas las citas.

28 El Correo Español, ciudad de México, 18 de febrero de 1898.

29 Entre los medios españoles que repitieron la noticia mediante telegrama oficial se pueden dividir en dos grupos, el primero corresponde a quienes lo publicaron en la edición del 16 de febrero: El Heraldo de Madrid, La Correspondencia Militar, La Época y La Iberia. El segundo grupo replicaron la noticia el 17 de febrero: El Año Político, El Globo, Correspondencia de España, El Siglo Futuro, El Imparcial y El Liberal.

30 La Correspondencia de España, Madrid, 17 de febrero de 1898. Cursivas en el original.

31 Hasta el momento y según los reportes de la prensa mexicana la cifra varía entre 250 y 260 fallecidos por la explosión. Por ejemplo el periódico El Imparcial del día 17 de febrero titula: “'Explosión del Maine', 253 muertos, se ignora la causa”. El Imparcial, ciudad de México, 17 de febrero de 1898.

32 New York Journal, New York, 17 de febrero de 1898. 
suceso también fue referido con celeridad por los periódicos mexicanos, ya que la proximidad de México al desarrollo de los acontecimientos, así como su historia ligada al devenir de Cuba, y a las pequeñas y poderosas comunidades española y norteamericana, dieron paso a un singular campo de batalla informativo sobre el hundimiento del buque de guerra a partir del 16 de febrero, cuando el diario The Mexican Herald tituló en su portada: "The Cruiser Maine". Terrible Explosion on Board the Warship, ${ }^{33}$ para dar a conocer el primer telegrama sobre la explosión del Maine recibido a la una de la madrugada. Así, los diarios de la ciudad de México se dedicaron a describir una y otra vez los confusos detalles de la terrible explosión del Maine.

\section{FUENTES Y CIRCUITOS DE INFORMACIÓN EN EL CASO DE LA NOTICIAS DEL MAINE}

Antes de analizar el contenido de las noticias sobre la explosión del Maine, es necesario interrogarse sobre cuáles fueron las fuentes y circuitos de información que usaron los diarios de la ciudad de México. Examinar este aspecto nos permite conocer dónde se originaron las noticias y a través de qué circuitos de información transitaban y, si es posible, establecer la relación entre la red de información, los bandos periodísticos y el tono del contenido. Para iniciar vamos a conocer cómo se distribuyó la noticia del Maine en la prensa capitalina. Recordaremos, entre el 16 y 22 de febrero de 1898 se registraron 657 noticias en los siguientes 15 títulos, los cuales podemos ver en la Tabla 1.

Como podemos observar, la explosión del Maine fue recogida en 13 diarios en español y dos en inglés. Gracias a la consulta y revisión de los diarios en lengua inglesa, fue posible enriquecer la base de datos creada, sobre todo porque nos interesa comparar el número de noticias, su contenido, así como vías telegráficas usadas para transmitir la información con los periódicos de habla castellana.

En cuanto al número de noticias publicadas por periódico podemos decir que la cobertura fue desigual, pues de las 657 noticias, 485 fueron dadas en español y 172 en inglés. A primera vista parecería que la prensa en inglés no reaccionó como se pensaba a la explosión del Maine. No obstante, un conteo más detallado indica que el diario The Mexican Herald fue el que más notas imprimió de toda la prensa capitalina con un total de 105. En segundo lugar fue El Correo Español con 103, seguido de El Universal con 68. En otras palabras, tan sólo The Mexican y El Correo Español representan un tercio

33 The Mexican Herald, ciudad de México, 16 de febrero de 1898. Cursivas en el original. 
Tabla 1

Número y títulos de la prensa de ciudad de México que publicaron noticias sobre el Maine, 16-22 de febrero de 1898

\begin{tabular}{llll}
\hline No. & \multicolumn{1}{c}{ Título } & No. & \multicolumn{1}{c}{ Título } \\
\hline 1 & Amigo de la Verdad & 9 & La Patria \\
2 & El Contemporáneo & 10 & El Popular \\
3 & El Continente Americano & 11 & Semanario Mercantil \\
4 & El Correo Español & 12 & El Universal \\
5 & Diario del Hogar & 13 & La Voz de México \\
6 & El Imparcial & 14 & The Mexican Herald \\
7 & El Municipio Libre & 15 & The Two Republics \\
8 & El Nacional & & \\
\hline
\end{tabular}

Fuente: HNDM.

del total de las notas. Estas cifras indican un interés concentrado en estos dosmedios, los cuales representaban los bandos estadounidense y español. Para más detalles presentamos la Gráfica 1 que recoge los porcentajes sobre la cobertura de la explosión del Maine por periódico, la cual refrenda la notable atención que recibió el evento en la prensa que respaldó los intereses estadounidenses y españoles.

Las noticias sobre el Maine en los bandos políticos detrás de los periódicos se encontraban bien diferenciadas, debido a su posición confrontada respecto al status de Cuba; por tanto la cuestión es ahora interrogarse sobre el cómo y el por qué se proveyeron de determinada información para elaborar sus relatos y el número de veces que ésta fue replicada.

De las 657 noticias publicadas en la prensa de la ciudad de México, estimamos que alrededor de un $80 \%$ provienen de telegramas, el resto corresponde a cartas, editoriales y cuatro publicaciones donde se transcribe el contenido de una llamada telefónica al general Blanco para comunicarle lo sucedido la noche del 15 de febrero. El tendido de cables telegráficos era un nudo en el Caribe, de manera que era necesario encontrar una metodología que nos permitiera conocer el origen y la trayectoria en el circuito de información por el que viajaban las noticias de los diarios capitalinos. 


\section{News Journals in Mexico}

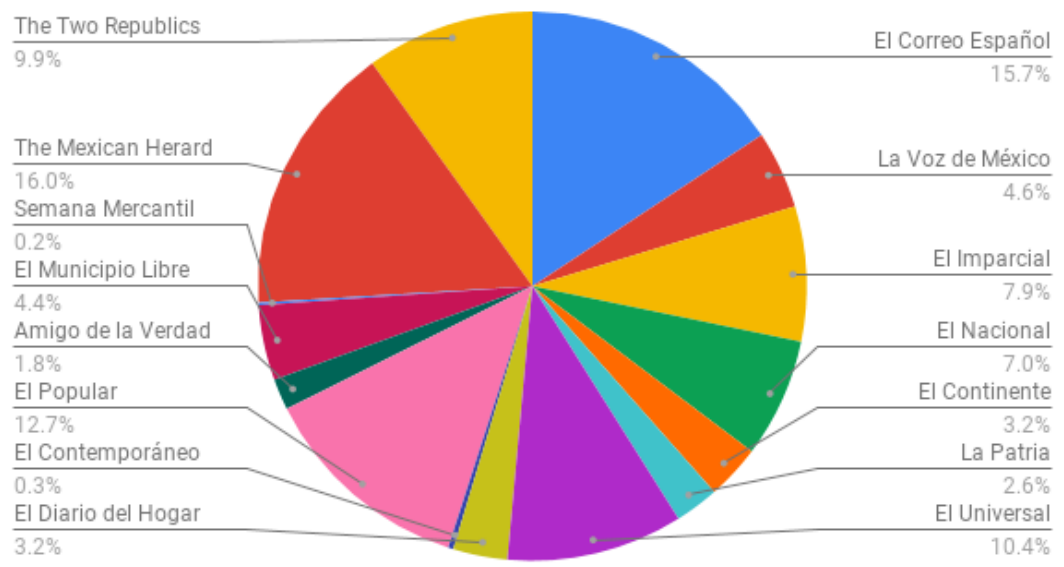

Gráfica 1. Porcentaje de la cobertura sobre la explosión del Maine en la prensa de la ciudad de México, 16-22 febrero de 1898.

Fuente: HNDM.

- Para ello se organizó, en primer lugar, el corpus de noticias del Maine con los siguientes campos o metadatos: fecha de publicación, periódico, ciudad de publicación, contenido de la noticia, lengua y fuente de la hemeroteca que se encontraban ya disponibles como Metadatos en la HNDM. Sin embargo, otros datos relevantes para la investigación como la fecha de origen de la noticia/telegrama la encontramos contenida dentro del cuerpo de la noticia, por lo que utilizamos un método automático para extraer esa información del texto. Lo anterior se llevó a cabo por medio de una metodología de lingüística computacional que consiste en identificar expresiones regulares para capturar ciertos patrones a partir de ahí. Una expresión regular es una secuencia de caracteres que permiten establecer patrones de búsqueda dentro de documentos de textos y filtrar las partes del texto que nos interesan. El procedimiento se puede resumir en las siguientes etapas generales:

- Identificar en las noticias entidades nombradas de tipo ciudad y meses del año (generalmente sólo febrero para el caso del Maine), así como identificar sus variantes ortográficas, esto es, diferentes tipos de abreviaturas y formas de escribir la palabra.

- Una vez identificadas las ciudades, meses y sus variantes ortográficas, se guardan en listas. 
- Por medio de estas listas y expresiones regulares, se extrae, para cada noticia, la región del texto que contiene una ciudad, mes y número.

Una vez concluidos estos pasos, la información obtenida se traslada a hojas de cálculo para complementar los campos (o metadatos) del corpus inicial.

$\mathrm{Al}$ tener fechas y ciudades de origen, fue posible graficar el tipos de información tomando en cuenta el flujo entre ciudad de origen-ciudad destino, cuyos resultados se pueden ver en las Gráficas 2 y 3, que muestran el lugar de origen de las noticias publicadas sobre la explosión del Maine en la prensa de la ciudad de México entre el 16 y el 22 de febrero de 1898.

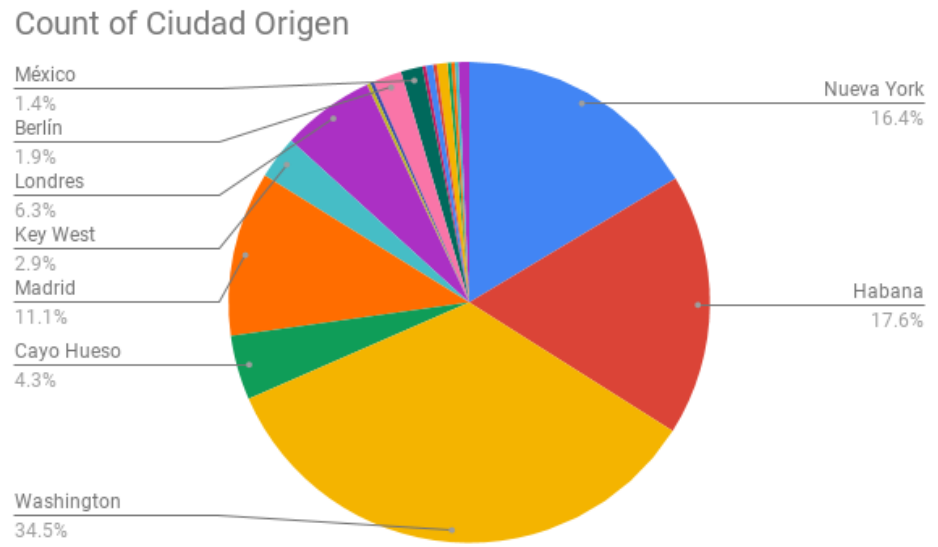

Gráfica 2. Lugar de origen de las noticias del Maine en la prensa mexicana escrita en castellano.

Fuente: HNDM.

Como podemos observar, tanto la prensa mexicana en castellano como en inglés presenta como principal ciudad de origen de las noticias a Washington y no La Habana, a pesar de que en este puerto fue donde tuvo lugar el suceso de la explosión del buque. Incluso, como podemos notar en la Gráfica 2, El Correo Español, del que podríamos suponer sus noticias tendrían como lugar de origen La Habana o Madrid, también provienen de Washington a pesar que varias de sus informaciones se obtuvieron mediante un servicio especial desde España y también con sede en La Habana. ${ }^{34}$.

34 El Correo Español contaba con el "Servicio Especial Telegráfico” y bajo este nombre titulaba la columna de noticias provenientes de La Habana, puesto que el servicio cubano 


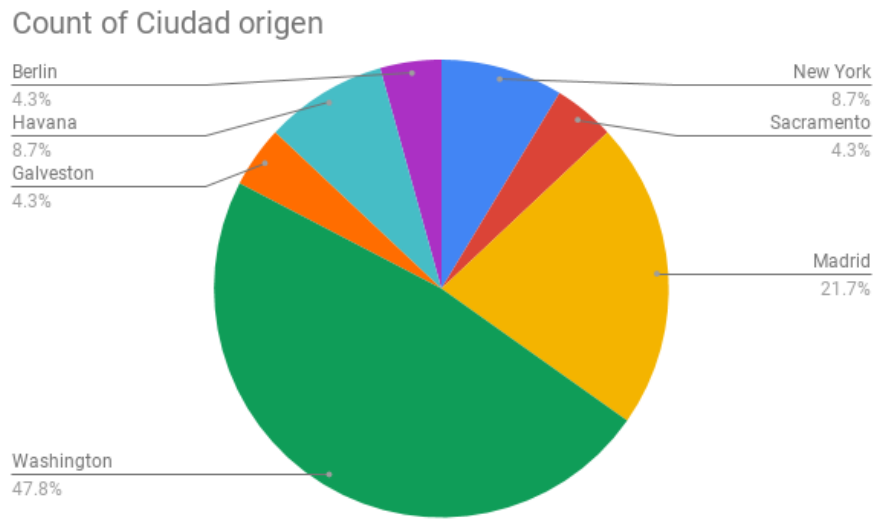

Gráfica 3. Lugar de origen de las noticias del Maine en la prensa mexicana escrita en inglés.

Fuente: HNDM.

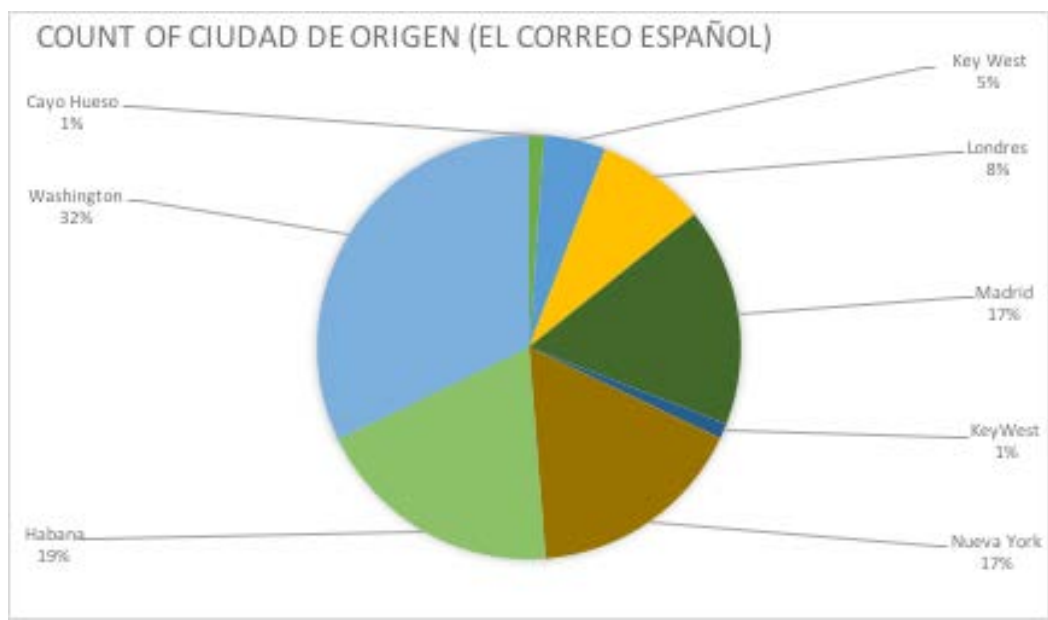

Gráfica 4. Porcentaje de los lugares de origen de las informaciones publicadas en el periódico El Correo Español, 16-22 de febrero de 1898. Fuente: HNDM.

permanecía bajo el control de las autoridades españolas, allí regía el Servicio de Transmisión de la Correspondencia Telegráfica, en funcionamiento desde 1883 y por la cual se autorizaba las rutas de comunicación locales y extranjeras. Véase también, Elizalde, El Correo Español, p. 48. 
Un comportamiento similar ocurrió con el resto de los periódicos que, a pesar de sus bandos, los principales lugares de origen de sus noticias provenían de Washington y otras ciudades norteamericanas, entre las que destacan New York y Key West. La excepción que registramos fue el caso de El Popular, acérrimo defensor de la causa española, ${ }^{35}$ el cual registró que la mayoría de sus noticias provenían de La Habana con un 25\%, seguido muy de cerca con un 23.4\% emitidas de Washington.

Como hemos mencionado, Washington y otras ciudades norteamericanas constituyeron los principales lugares de origen de las noticias publicadas por la prensa de la ciudad de México tanto en castellano como en inglés. Sin embargo, las Gráficas 5 y 6 nos muestran un matiz interesante y es que, a pesar de que Washington no pierde su hegemonía a lo largo de la cobertura que estudiamos del 16 al 22 de febrero, es notable observar que La Habana y luego Madrid se conservan en el segundo y tercer lugar. Como es lógico suponer, esto se debe a que la explosión del Maine ocurrió en La Habana, mientras que la presencia de Madrid nos sugiere que la información sobre este acontecimiento fue de notable atención para España, pues se trataba todavía de su isla.

Las gráficas referidas también nos indican la evolución en la cantidad de notas publicadas en la prensa mexicana. Así podemos observar que la Gráfica 5, recoge el mayor número de noticias sobre el Maine, período que corresponde a los primeros tres días del evento, mientras que la Gráfica 6, exhibe un menor número de notas, es decir, conforme pasaron los días, el suceso del Maine perdió interés al menos en términos generales.

Para entender mejor a qué se debió el predominio de diferentes lugares de los Estados Unidos, como sitios de origen de la notas publicadas de la ciudad de México sobre el Maine, es necesario tomar en cuenta que la ciudad de Galveston era el punto central de la compañía de telégrafo entre Estados Unidos y México, puesta en marcha desde $1881,{ }^{36}$ aunque la construcción de la estación y tendido de los cables hubiese iniciado dos años

35 Rojas, "Retóricas de la raza”, pp. 602-603.

36 El Republicano informa que el Cable Submarino "parece que a mediados del presente mes, comenzará a funcionar el que une nuestras costas del Golfo con las de los Estados Unidos. A Veracruz han llegado dos ingenieros con el fin de dirigir los trabajos y establecer allí una oficina, debiéndose establecer otra en esta capital”. El Republicano, ciudad de México, 13 de enero de 1881. Este nuevo proyecto incluyó el tendido total desde el centro del país hasta la costa y de ahí con Estados Unidos y el Mundo: "La Empresa del Cable Submarino.- según dice, esa empresa ha terminado sus trabajos para la instalación de un hilo telegráfico que una la ciudad de Veracruz con México”. La Voz de México, ciudad de México, 29 de septiembre de 1881 . 


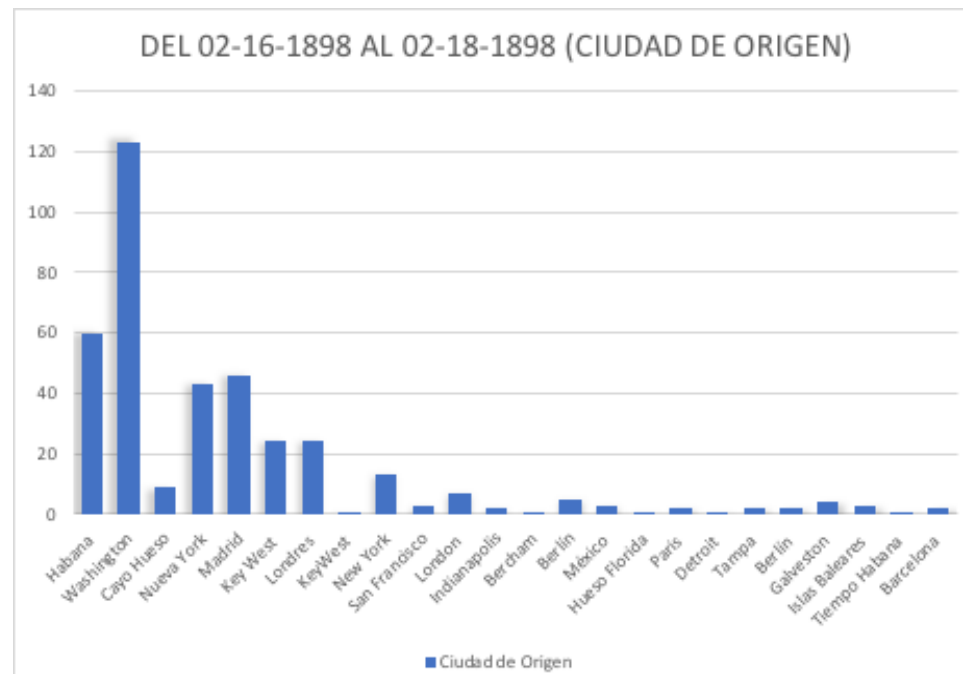

Gráfica 5. Evolución de los lugares de origen de las noticias en la prensa de la ciudad de México (inglés y español), 16-18 de febrero de 1898. Fuente: HNDM.

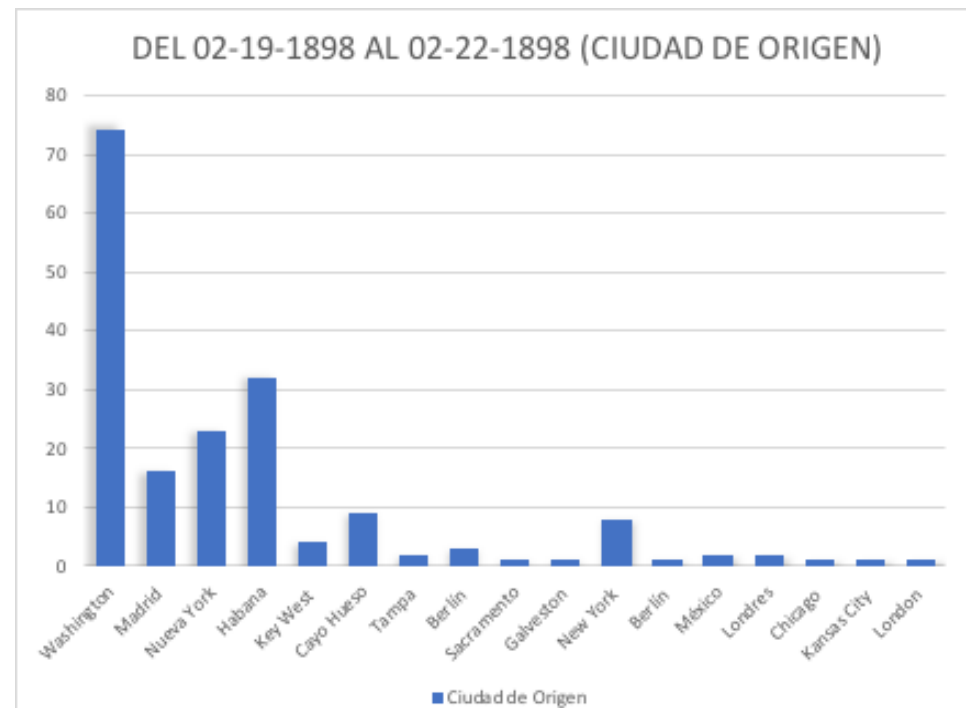

Gráfica 6. Evolución de los lugares de origen de las noticias en la prensa de la ciudad de México (inglés y español), 19-22 de febrero de 1898. Fuente: HNDM. 
antes con la entrega de la concesión a la empresa The Mexicam Cable Company. ${ }^{37} \mathrm{La}$ instalación de esta red transatlántica permitió a México hacer parte de la lista de principales ciudades del mundo con extraordinarios avances en telecomunicaciones, fue tal el impacto que los diarios como La Libertad señalan:

Se espera que la línea quedará abierta para el 25 de Enero de 81, y entonces Veracruz estará a quince minutos de Nueva York y a veinticinco minutos de Londres y de París [...]. Puede formarse una idea de la ventaja que México conquista con el establecimiento del nuevo cable, considerando que Nueva York dista telegráficamente del Japón una hora y cincuenta minutos, Australia una hora treinta minutos, Bombay una hora, Lisboa cuarenta y cinco... Habana nueve minutos. ${ }^{38}$

Esto explica por qué muchas de las noticias asientan la leyenda "Vía Galveston”, o servicio exclusivo Vía Galveston, de ahí la prensa capitalina se nutría en parte de la red de información de los Estados Unidos.

Pese a la presencia diplomática de España en Cuba y Washington, y a la intensa antesala que sus funcionarios ofrecieron para tratar de controlar cualquier determinación de guerra por parte de Estados Unidos, éstos consiguieron mantener el predominio en la publicación de noticias y el control de los cables, aun cuando cada uno de los dos bandos contaba con sus propios tendidos trasatlánticos en América y en el Caribe, en particular. De hecho, conforme pasaron los días, la balanza informativa se terminó por inclinar hacia los Estados Unidos; esto se debió a la creación de una comisión americana para la investigación sobre el hundimiento del Maine, tras lo cual el gobierno estadounidense procedió —en fechas posteriores a la presente investigación-, es decir, después del 22 de febrero, a aplicar un bloqueo a la isla de Cuba desde distintos frentes.

Uno de esos frentes fue enviar naves de guerra a las aguas limítrofes del territorio cubano, el diario español La Correspondencia en un largo editorial discute sobre "el bloqueo al que nos somete el gobierno yankee [...] que ese bloqueo por sí mismo constituye un casus belli, porque hemos sostenido que hubo agresión a nuestra soberanía y atentado al derecho de gentes con el solo envío del Maine”. ${ }^{39}$ Así, se mostraba el poderío de Estados Unidos, con la exhibición de una flota envidiable y temible que materializó en pocos días su postura a favor de una guerra contra España.

\footnotetext{
37 Mendoza Vargas, “El territorio y la innovación”, p. 102.

La Libertad, ciudad de México, 9 de enero de 1881.

39 La Correspondencia, Madrid, 7 de marzo de 1898.
} 
Estas referencias del bloqueo son importantes porque la orden de cortar los cables telegráficos desde y hacia la isla fue posible gracias a la tripulación de las naves que aplicaron el bloqueo. Finalmente, Estados Unidos cumplía su cometido, impedir la emisión o recepción de telegramas entre Cuba y el Mundo en el mes de mayo de $1898 .{ }^{40}$ Ejemplo de ello es la nota publicada por el diario El Día de Madrid, que registró las operaciones en la columna "Cables":

No obstante haber asegurado los comandantes de los buques americanos "Marblehead” y "Naswille”, que habían cumplido las órdenes recibidas de su Gobierno, cortando los cables en Guantánamo y en Cienfuegos, la noticia no ha resultado exacta. Esto ha producido gran disgusto en Washington, y como consecuencia de ello, han enviado a [buque] Sampson que corte dichos cables. Veremos si el famoso almirante [...] logra cubrirse de gloria llevando a cabo la peligrosa operación de cortar las comunicaciones. ${ }^{41}$

De esta forma, se concretaba la puesta en marcha de un capítulo de la guerra hispanoamericana en el plano de las comunicaciones y la libre información, ${ }^{42}$ así como, el crecimiento y poderío de Estados Unidos en la región y la pérdida del último territorio de la monarquía española en América.

\section{DESCRIPCIÓN, ESPECULACIÓN YTENSIÓN DIPLOMÁTICA: TRES MOMENTOS DE LA COBERTURA DEL MAINE EN LA PRENSA DE LA CIUDAD DE MÉXICO}

Para conocer el desarrollo de los contenidos de la cobertura del Maine en la abundante información suministrada por los distintos periódicos de la ciudad de México, utilizamos la técnica TF-IDF para identificar automáticamente los términos que caracterizan un texto particular dentro de una colección

40 La Época, periódico publicado en Madrid, denunció en su edición del 4 de mayo de 1898, bajo el título “Fortificaciones -La intervención de los cables” que el Congreso de Estados Unidos aprobó la construcción de fortificaciones, y "Las compañías norteamericanas que explotan cables submarinos de los comprendidos en la línea Transandina y costas del Pacífico han recibido órdenes terminantes de Washington para no transmitir ningún despacho relacionado con la guerra sin la previa censura de las autoridades yankees. Como se ve, el propósito de los Estados Unidos es aislar por completo a España de sus posesiones para que no puedan llegar otras noticias que aquellas que convengan a los intereses norteamericanos”. La Época, Madrid, 4 de mayo de 1898.

41 El Día, Madrid, 28 de mayo de 1898.

42 "Más periodistas presos. Un telegrama de la Habana da cuenta de haber sido apresados cerca de Matanzas, en el momento de intentar desembarcar, dos periodistas de nacionalidad inglesa”. La Época, Madrid, 30 de mayo 1898. 
más grande de documentos. ${ }^{43}$ Para poder analizar los resultados, nos interrogamos si las palabras clave cambiaban en el transcurso de los días y si se agrupaban unas con otras en particular. De ahí recurrimos al procesamiento del lenguaje natural (PLN), n-gramas es un término común que se utiliza para referirse a una secuencia continua de $n$ elementos. En nuestro caso, un bigrama se refiere a secuencias de dos palabras, mientras que un unigrama corresponde a una sola palabra. Por lo tanto, las palabras clave (keywords) bigramas, equivalen a extraer secuencias de keywords formadas por dos términos, o palabras, ejemplo: autoridades españolas. Esto nos permitió observar que los términos clave sí cambiaban en el tiempo, pues su nivel de relevancia es fluctuante. Por ejemplo, si bien la palabra “explosión” está presente en toda la cobertura periodística estudiada, ésta se concentró en los primeros dos días. En cambio, la palabra “guerra” apareció hacia el final de nuestra muestra.

El examen de estas palabras clave continuó tras advertirse que podían agruparse en categorías según su significado. Para ello se hizo uso del reconocimiento de entidades nombradas, NER (Name Entity Recognition), que consiste en identificar palabras o conjuntos de palabras dentro de un texto, mismas que pueden pertenecer a una categoría predeterminada, como personas (PER), localizaciones (LOC) y organizaciones (ORG). ${ }^{44}$ Adicionalmente, para algunas lenguas (principalmente el inglés) es posible una clasificación más granular, como los grupos (nacionalidades) o los eventos (huracanes, deportes). ${ }^{45}$

Los resultados indicaron que en la entidad LOC que atañe al espacio geográfico, resalta por su dominio la palabra Washington, cuya importancia

43 En nuestro caso, se le asigna un score alto a aquellas palabras que son frecuentes dentro de una noticia, pero son poco frecuentes en el resto de la colección. La técnica utilizada para obtener este puntaje, o score, es llamada TF-IDF (Term-frequency, inverse document frequency). Es una técnica estadística que asigna un score a una palabra basándose en conteos de las veces que aparece este término en un documento específico, así como el número de documentos de toda la colección que contienen al término en cuestión. La fórmula básica para calcular el score TFIDF de un término, dentro de un documento $d$, que pertenece a una colección de documentos $D$. Sparck Jones, “A Statistical Interpretation of Term Specificity”, pp. 11-21; Manning, Raghavan y Schutze, “Scoring”, pp. 102-104.

44 Para más detalles, véanse Finkel, Grenager y Manning, “Incorporating”, pp. 363-370; Mansouri, Affendey y Mamat, “Named Entity Recognition Approaches”, pp. 339-344.

45 Existen diversos métodos para realizar este reconocimiento automático. Primero se utilizan heurísticas, relativamente sencillas para detectar entidades nombradas en el texto, por ejemplo, detectar aquellas palabras que empiezan con mayúsculas, que tienen una puntuación o formato especial, como: cantidades, fechas, abreviaturas etc. Posteriormente, se debe clasificar qué tipo de entidad es cada una de estas palabras. Para lograr lo anterior, generalmente se usan grandes listas o lexicones de entidades nombradas dependientes de cada lengua, complementadas con métodos automáticos de aprendizaje de máquina (machine learning). 
pudimos comprobar con el estudio de los lugares de origen de las noticias del Maine y como sede de las disputas diplomáticas e informativas. La entidad PER reveló que las fuentes de información fueron expedidas de forma oficial por diferentes autoridades de los gobiernos español y norteamericano. Esto sugiere una suerte de escalada diplomática que tomó el evento del Maine. Mención aparte merece el caso del Capitán Sigsbee, cuya figura y testimonios constituyen una pieza clave en el desarrollo de las noticias del Maine (desde el punto de vista oficial/institucional de los Estados Unidos. La entidad ORG sugiere una preponderancia de las instituciones estadounidenses, como Gobierno, Marina, Cónsul General y Congreso.

La Tabla 2 ilustra precisamente las diez entidades nombradas principales obtenidas en nuestra base de datos. Destaca, como ya mencionamos, el peso de los representantes e instituciones norteamericanas y españolas. Sobresalen también dos periódicos, El Mundo y El Imparcial, esto se debe a que en muchos casos se menciona un servicio especial de cablegramas en las noticias publicadas sobre el Maine en este último. ${ }^{46}$

\section{Tabla 2}

Número de las entidades nombradas más mencionadas en español en la prensa de la ciudad de México, 16-22 de febrero de 1898

\begin{tabular}{llll}
\hline No. & \multicolumn{1}{c}{ LOC } & \multicolumn{1}{c}{ ORG } \\
\hline 1 & Washington & Sigsbee & Gobierno \\
2 & España & General Blanco & El Mundo \\
3 & Habana & Presidente & Marina \\
4 & Nueva York & Ministro de marina & El Imparcial \\
5 & Madrid & Alfonso XII & Cónsul General Lee \\
6 & Estados Unidos & Secretario Long & Congreso \\
7 & Vizcaya & Mariscal Blanco & Capitán Sigsbee \\
8 & Cuba & Presidente McKinley & Ministro de Marina \\
9 & Londres & Olivette & Gabinete \\
10 & México & Príncipe & Merrit \\
\hline
\end{tabular}

Fuente: HNDM.

46 Véase por ejemplo una nota de El Imparcial del 18 de febrero de 1898, que dice: "CABLEGRAMAS DE SOBERANOS LA PRENSA ESPAÑOLA Servicio especial para El Mundo y El Imparcial. Berlín, Febrero 17.- Inmediatamente después que se recibieron las noticias sobre el desastre del $<$ Maine $>$ y fueron comunicadas al Emperador Guillermo, ésto envió un cablegrama al Presidente McKinley, expresando su hondo pesar por las desgracias personales ocurridas en la catástrofe y por la pérdida del buque”. El Imparcial, ciudad de México, 18 de febrero de 1898. 
Con base en los resultados que arrojaron las herramientas digitales, se estableció que la prensa mexicana presentó tres momentos en la narrativa de la noticia, a saber: 1) La descripción del evento, con énfasis en la explosión; 2) La especulación en la que se debatió la calificación del evento, es decir, si se trataba de un desastre, una catástrofe en la pudo o no intervenir un torpedo y, 3) Se trata de relatar el desarrollo de las consecuencias del evento, tanto la interpretación sobre el suceso: visto como un terrible accidente que anunciaba una crisis diplomática.

\section{EL REPORTE DE LA EXPLOSIÓN}

Como era de esperarse, el principal periódico de habla inglesa en México, The Mexican Herald fue el primero y único en transmitir, al siguiente día de la explosión, la transcripción de dos telegramas gracias a un cable The Associated Press emitido a las 2:15 de la madrugada, proveniente de Arkansas, quien había recibido, a su vez, notificación de La Habana a la 1 de la madrugada: "Night chief operator Shell at the St. Louis Western Union office has reported that he has received a report from New Orleans to the effect that the United States battleship "Maine" was blown up in Havana harbor at 11:30". ${ }^{47}$

La prensa escrita en español y publicada en la ciudad de México ofreció una generosa cobertura a la noticia que en sus primeros momentos pareció liderada por impresos como El Correo Español, al ser un diario que recibía directamente de La Habana en constante enlace con las notas oficiales emitidas desde la península. El primer telegrama recibido desde la isla lo registró el 17 de febrero, aunque emitido el día anterior, se informa que pasadas las diez de la noche "hubo una espantosa explosión á bordo del crucero americano "Maine", en el puerto de la Habana. Muchos de la tripulación murieron y otros resultaron heridos"... ${ }^{48}$

En esta primera cobertura sobre la explosión del Maine se insistía en la necesidad de esperar los telegramas de la Prensa Asociada (The Associated Press), pues se desconocían las causas de tal siniestro. En total se reseñan nueve telegramas publicados en esta sola edición del El Correo Español, comenzaron las especulaciones sobre las causas del hundimiento, el número de fallecidos se incrementó con el paso de las horas e incluso se publicó afirmaciones que posteriormente debieron ser desmentidas como: "El capitán del <Maine, $>$ Mr. Sigsbee, fué gravemente herido en la cabeza por la

47 The Mexican Herald, ciudad de México, 16 de febrero de 1898.

48 El Correo Español, ciudad de México, 17 de febrero de 1898. 
explosión que se produjo á bordo de un navío”. ${ }^{49}$ Esta misma línea editorial la siguieron los demás diarios escritos en español, aunque El Imparcial fue el único, en este primer día de cobertura, en titular "La Explosión del Maine, 252 muertos":

Habana, Febrero 16.- Se tienen mayores detalles sobre el desastre del crucero americano <Maine>, que voló como á las nueve y cuarenta minutos de la noche. Se cree que todos los oficiales se han salvado, pero á Jenkeins y Merritt, no se les encuentra.

La causa de la explosión no se ha investigado aún. El Capitán General, el ejército y los oficiales de la marina española, han prestado toda la ayuda posible.

La noticia de que el Capitán Sigsbee estaba herido es infundada, pues él y la mayor parte de los oficiales escaparon en un pequeño bote dirigiéndose al vapor <City of Washington> de la línea Ward. Se nos dice que no se encuentran á doscientos de los marineros, además de los dos oficiales ya nombrados. Se nos comunica que muchos marineros se salvaron nadando hacia un bote. Seis de los marineros heridos y uno de los oficiales han sido conducidos al hospital militar por orden del General Blanco. ${ }^{50}$

El paulatino incremento de noticias, tanto en español como en inglés, es notorio, detalles sobre el tema más relevante para los dos actores políticos con relación a las posibles causas del hundimiento se tomó un alto porcentaje de estas primeras publicaciones. Aunque también son visibles, entre el 17 y 18 de febrero, extensos textos que detallan el rescate de los cuerpos y la forma como los marineros recibirán sepultura en la isla, ${ }^{51}$ este minucioso

50 El Imparcial, ciudad de México, 17 de febrero de 1898.

51 El día 17 de febrero los diarios El Nacional, La Voz de México, El Imparcial, El Continente Americano y La Patria replicaron casi la misma información: hora y lugar del siniestro, hundimiento total del acorazado, el estado del Capitán Sigsbee y los demás miembros de la tripulación, así como el inicio de la investigación. De este grupo, solo El Nacional reseñó la entrevista a un sobreviviente: "El cocinero de á bordo ha sido el menos herido, con grandes dificultades pudo declarar lo siguiente: Estaba acostado en mi hamaca; eran cosa de las ocho de la noche. Escuché tres campanadas. Después yo no recuerdo nada hasta el momento en que me sentí lanzado al aire dando muchas vueltas. Luego caí como una masa sobre el puente. Estaba yo rodeado de humo. El puente, es decir, el lugar en que me hallaba se sumergía en el agua. Salté para no ahogarme. En este momento fui recogido por un bote de un buque de guerra español, en donde se encontraban cuatro compañeros míos, igualmente salvados. La explosión se produjo, según creo, en el lugar en que se guarda el algodónpólvora para los torpedos. En el agua no flotan más que los amarres del buque; lo demás se ha sumergido. El Nacional, ciudad de México, 17 de febrero de 1898. Cursivas en el original. 
trabajo de los rescatistas fue seguido de cerca por las autoridades españolas establecidas en Cuba, ya se dejaban ver las primeras tensiones diplomáticas con el gobierno estadounidense sobre el control de los cables y la hipótesis del siniestro que se manejaba de ambos lados.

\section{LA ESPECULACIÓN:}

\section{LOS RUMORES SOBRE EL HUNDIMIENTO DEL MAINE}

Las causas del evento ocuparon las primeras notas de los diarios norteamericanos y españoles, ninguno de los bandos se contuvo de lanzar hipótesis sobre lo acontecido, aún sin pruebas, los periódicos tomaron activa participación en la creación de una opinión generalizada y pública sobre el Maine. Para los diarios de habla inglesa la posible explosión podría haberse ocasionado por dos razones: la primera, la instalación de un artefacto introducido a su llegada a la isla para destruir deliberadamente el buque o; en segundo lugar, el disparo de un torpedo desde la isla, esta última fue adoptada con mayor convencimiento. The Mexican Herald puede considerarse como el diario con más activa participación en contribuir a los rumores sobre el hundimiento del Maine:

THE LOSS OF THE "MAINE. In the present tense state of public opinion in the United States and Spain, the tremendous news of the destruction of the warship "Maine" in Havana harbor comes to excite popular sentiment to the highest pitch. Ever since the "Maine" reached Havana, the sentiment of the populace has been growing more and more bitter, and it is quite conceivable that some plot, in which officers of the army or navy were concerned, was hatched, and an engine of destruction launched in the darkness of night against the hated Yankees craft. ${ }^{52}$

Éstas y otras comunicaciones subidas de tono sobre el suceso permitieron entender con mayor agudeza que algunos medios defendían con ímpetu esta versión del evento. ${ }^{53}$ A las especulaciones sobre una supuesta intención de

52 The Mexican Herald, ciudad de México, 17 de febrero de 1898.

53 Este mismo diario de habla inglesa publicado en la Ciudad de México transmitió la opinión de otros medios como The London Globe emitida el 16 de febrero: "The Globe this afternoon, referring to the disaster to the United States, battleship Maine, says: "It is impossible to refrain from a suspicion that the explosion may have been caused by foul means. Although anchored, the Maine would have steam up in one of her boilers for her dynamos and auxiliary machinery. If an infernal machine was hidden in the coal aud thrown into the furnace, obviously there would be an explosion of the boiler, and, as a result, of the magazine. That this terrible event should have occurred in the harbors of Havana, has rencered a 
dañar el Maine se unió, como era de esperarse, The Two Republics, con fuertes editoriales y telegramas que lanzaban día a día diferentes teorías conspirativas. Se trató de la mayor avanzada comunicacional a favor de Estados Unidos desde que inició el conflicto entre los dos gobiernos por la insurrección cubana suscitada ya varios meses atrás. The Two Republics mantuvo una postura periodística que no temía la declaratoria de guerra y se sentía seguro del dominio informativo en la región, como podemos ver a continuación:

\begin{abstract}
SOME EXPERT OPINIONS.
WASHINGTON, Feb. 16.- Owing to the lack of detailed information regarding the disastrous destruction of the battleship "Maine" in the harbor of Havana, many conflicting theories are advanced as to the cause of the explosion. The ordnance experts at the Navy department are mostly agreed that the primary cause was from outside contact, probably a mine or torpedo which blew in the side of the ship near the forward magazine and those adjacent then ignited and blew up, wrecking the quarters of the crew. The "Maine" had on board a small quantity of smokeless powder, but a large supply of brown powder. ${ }^{54}$
\end{abstract}

También, dentro del grupo de periódicos que cubrieron la explosión del Maine y que estaban abiertamente a favor de Estados Unidos, tenemos el caso de El Imparcial, ${ }^{55}$ además de los dos de habla inglesa arriba mencionados.

Al mismo tiempo, otra parte de los periódicos procuró narrar los pormenores del siniestro y sus víctimas; en paralelo otros, quizás la mayoría de diarios nacionales, fueron los más cautelosos en asentar que aún no era posible determinar su causa, tal fue el caso de los periódicos proespañoles, entre los que se hallan El Universal, El Popular, El Correo Español y La Voz de México. Transcurridos los dos primeros días del siniestro y tras versiones

solution of the mystery of international importance”. The Mexican Herald, ciudad de México, 17 de febrero de 1898.

54 The Two Republics, ciudad de México, 17 de febrero de 1898.

55 "UN TORPEDO FLOTANTE EN LA EXPLOSION. Cayo Hueso, Florida, Febrero 17.- El corresponsal de la Prensa Asociada acaba de regresar aqui á bordo del <Olivette> de la escena del desastre del "Maine” en el Puerto de la Habana. Los que están trabajando encontraron un agujero en el casco. El almirante Manterola citó al capitán Sigsbee á comparecer ante el Juez militar Peral, para hacer las declaraciones necesarias. Todas las pruebas de trabajo de torpedo serán examinadas [...] El mismo corresponsal estaba seguro desde la llegada del "Olivette” que el capitán Sigsbee está bajo la impresión de que el <Maine> fué volado por un torpedo flotante; y que había comunicado sus impresiones á las autoridades de Washington”. El Imparcial, ciudad de México, 18 de febrero de 1898. 
encontradas sobre los acontecimientos en la isla, El Popular reseñó de forma certera la situación caótica del momento:

"Habana, febrero 17,- Toda la prensa se ocupa extensamente de la explosión del "Maine”. Varios periódicos condenan la versión de que la explosión pudo ser intencional; otros comentan el incidente y todos procurar demostrar que no hay motivo para los comentarios de pesimismo, respecto á un probable combate naval entre España y los Estados Unidos”. ${ }^{56}$

Por su parte, El Universal a través de su "servicio cablegráfico exclusivo” del día 18 de febrero, dedicó su primera página al Maine, por primera vez en la cobertura de medios mexicanos se presentaba a los lectores una ilustración del acorazado acompañado de la transcripción de mensajes recibidos de otras partes del mundo, como éste emitido desde la capital inglesa titulado El desastre del $<<$ Maine $>>$ :

Londres, Febrero 16.- El corresponsal de la Prensa Asociada comunicó esta mañana al Embajador de España la noticia del desastre ocurrido al acorazado $<<$ Maine en la bahia de la Habana, quien después de deplorar el desastre, dijo que la explosión debe haber sido un accidente, toda vez que el $<<$ Maine $>>$ se encontraba en la Habana haciendo una visita de amistad. ${ }^{57}$.

Por otra parte, destacan entre el total de diarios mexicanos, los abiertamente procubanos, es decir, quienes apoyaban y alentaban se le permitiera a Cuba su independencia de España, pues a la par del cubrimiento a la explosión del Maine ofrecieron a sus lectores información sobre la guerra civil que se desarrollaba en la isla. De los medios revisados, se identifican: El Continente Americano, Diario del Hogar y La Patria.

De este grupo, El Diario del Hogar fue el periódico con más noticias registradas sobre la explosión del Maine en nuestro rango temporal de investigación. Entre sus particularidades está la notoria la distancia en el cubrimiento de la noticia porque su discurso es más neutral y el uso de las palabras es respetuoso, además, sus textos son carentes de exaltaciones apasionadas hacía un lado u otro de la disputa diplomática, como era habitual en algunos de los otros medios. Aunque esta aparente neutralidad no impidió seguir la misma línea editorial de los demás diarios: una primera fase de especulaciones, opiniones encontradas, seguido de una etapa para dar a conocer las notas sobre las investigaciones $\mathrm{y}$, por último, una de opiniones

57 El Universal, ciudad de México, 18 de febrero de 1898. 
oficiales con la esperanza de atenuar los ánimos de Guerra. ${ }^{58}$ Así por ejemplo, luego de varios reportajes del hundimiento del Maine y de presentar un balance sobre las diversas opiniones, El Diario del Hogar publicó: "La catástrofe del Maine es objeto de las conversaciones entre Diputados y Senadores; gran número de estos representantes han accedido a los Ministerios de Marina y de Relaciones para obtener detalles. A la recepción de los primeros despachos, se ha reparado que los hombres políticos vacilan en expresar sus opiniones". ${ }^{59}$ En términos generales, estos periódicos intentaron, pese a la superioridad del control de la información por parte de los medios a favor de Estados Unidos, ofrecer otras voces sobre la crisis política iniciada luego de la explosión del acorazado.

\section{LA ESCALADA DIPLOMÁTICA}

Desde el 19 de febrero de 1898, se advirtió que la emisión de la información sobre la voladura del Maine se concentró en manos de las autoridades estadounidenses. En este sentido, encontramos que conforme pasaba el tiempo, tanto los miembros del Congreso en Washington como los funcionarios de los departamentos de Guerra y de Relaciones tomaron y acapararon la palabra sobre el asunto. Además, según El Universal y El Nacional, el ministro de Marina de los Estados Unidos, recibió un despacho en el que el Consejo de Guerra conformaría una Comisión Investigadora, cuyo principal objetivo era determinar las causas de la explosión del Maine. ${ }^{60}$ Sin embargo, esta Comisión fue integrada únicamente por especialistas norteamericanos a petición del presidente McKinley, como podemos ver a continuación:

Hoy decidió el Presidente McKinley, después de una conferencia con los Secretarios de Estado, no acceder á la petición de que á los comisionados españoles en Cuba nombrados para el efecto, se les permita unirse con los comisionados americanos y hacer las investigaciones sobre el desastre del "Maine". ${ }^{61}$

58 Así por ejemplo, en medio de las dos posturas y reclamaciones de los involucrados en el conflicto producido por el hundimiento del Maine, publicaba: “OPINIONES DIVERSAS. Una de las opiniones que anoche tenía más eco, sin duda alguna, por lo que decían los españoles, era que el desastre fué originado por algún cubano, para provocar una guerra entre los Estados Unidos y España. También se decía que el suceso pudiera haber sido ocasionado por algún enemigo de los Estados Unidos; pero esta opinión no tenía gran eco. Los americanos en general sí creen que los españoles son los autores de la catástrofe”. El Diario del Hogar, ciudad de México, 18 de febrero de 1898.

59 El Diario del Hogar, ciudad de México, 19 de febrero de 1898.

60 El Universal, ciudad de México, 19 de febrero de 1898 y El Nacional, ciudad de México, 19 de febrero de 1898.

61 El Imparcial, ciudad de México, 20 de febrero de 1898. 
De esta manera, la política control de la información sobre el Maine por parte de los Estados Unidos respondió a una estrategia dirigida desde el presidente. Esta restricción informativa alcanzó hasta los dichos del capitán Sigsbee, capitán del Maine, quien había sido una de las fuentes más socorridas sobre la descripción del evento. Por ejemplo, a decir de El Nacional, Long, el Secretario de Marina, mediante un cablegrama solicitó a Sigsbee que aclarara unos rumores en torno a una supuesta declaración en la que se aseguraba que el barco había explotado a causa de una mina submarina. ${ }^{62}$ En su defensa, Sigsbee contestó que algunas de las entrevistas que circulan eran falsas, pues aseveró que no había dado a conocer su opinión sobre la catástrofe. ${ }^{63}$

A la par que los Estados Unidos trataban de acaparar lo que se sabía de las causas de la explosión del Maine, otras voces institucionales dejaron entrever una escalada diplomática tanto a favor como en contra de una guerra hispanoamericana. La averiguación sobre lo que provocó el estallido del buque de guerra era apremiante, tal como apuntó El Universal: "la situación es gravísima y llegará á su crisis, si las noticias que lleguen más tarde indican que el desastre no fue puramente accidental". ${ }^{64}$ Tal y como podemos suponer, si los resultados de la investigación concluían que se trató de un acto deliberado, la intervención bélica norteamericana sería inminente. De ahí que la tensión y la incertidumbre son evidentes en las palabras de los representantes de los gobiernos español y estadounidense.

Los infortunios de los buzos en el rescate de los cuerpos más el mal clima en el puerto caribeño retardaron las pesquisas de la investigación de la Comisión, situación que no hizo otra cosa que crispar los nervios en las cancillerías. El gobierno de España enfrentaba el peor de los escenarios, pues a menos de que se demostrara que la explosión del Maine fue causada por una falla interna, el país europeo sería responsable del evento, cuya sanción se vislumbraba más que severa. En este tenor, es comprensible ver numerosas muestras de respeto y condolencia de diferentes autoridades peninsulares desde el inicio de la cobertura de la noticia. Por ejemplo, El Diario del Hogar publicó lo siguiente: "Un despacho especial de Madrid dice que todas las dificultades políticas a la especie de hostilidad que reinaba contra los Estados Unidos han sido olvidadas, para dar lugar a un sentimiento de verdadera piedad por las víctimas del acorazado "Maine". ${ }^{65}$

62 El Nacional, ciudad de México, 21 de febrero de 1898.

63 El Imparcial, ciudad de México, 22 de febrero de 1898.

64 El Universal, ciudad de México, 18 de febrero de 1898.

65 Diario del Hogar, ciudad de México, 19 de febrero de 1898. 
Como podemos advertir, la administración española deseaba evitar un enfrentamiento a toda costa, de manera que no cesó en dar condolencias a través de diferentes voceros oficiales. Esto explica por qué El Correo Español estuvo colmado tanto de muestras de pesadumbre por el suceso, así como de afirmaciones que calificaron con insistencia la voladura del Maine como un "desastre", como vemos a continuación: "Todos los miembros del Cuerpo Diplomático y del Gobierno español han enviado una carta de condolencia á la Legación americana por el desastre del "Maine” y por las víctimas que perecieron". ${ }^{66}$ En este afán, El Correo insertó el telegrama que envió el presidente de la república mexicana, Porfirio Díaz a su homólogo norteamericano, expresando también su pena por el siniestro ${ }^{67}$ En este contexto tan frágil para la posición peninsular, fue un escándalo la aparición de una supuesta circular dirigida a los españoles en la que se convocaba a declarar la guerra contra los Estados Unidos, misma que avivó el fuego de las sospechas, pues dio motivo a especulaciones sobre si los norteamericanos la habían escrito y hecho circular "con el fin de aumentar las dificultades entre España y los Estados Unidos”. ${ }^{68}$

Los temores de los españoles no estaban infundados, pues desde el inicio de la cobertura en la prensa mexicana, algunas opiniones de políticos y periódicos norteamericanos exigían dar un ultimátum a España e incluso se reportaba que en los astilleros no se dejaba de trabajar esperando la casus belli. ${ }^{69}$ Sin embargo, también se hicieron presentes otras voces alegando moderación, como fue el caso del senador estadounidense Butler, quien señaló

que en justicia no puede hacerse responsable á España directamente del desastre, aunque éste hubiera sido ocasionado por algunos españoles, pues hay que tener en cuenta que si el Gobierno no tuvo una participación directa, no puede ser culpable, y que se espera que si de las investigaciones resultara que uno ó unos iberos fueron los autores del siniestro se les aplicará un castigo ejemplar. $^{70}$

Otros miembros del Congreso hablaban no de iniciar una guerra, pero sí de fincar responsabilidades e indemnizaciones a España, como 100000 pesos oro por cada vida más del valor del buque y el cargamento. ${ }^{71}$ En este

Ibíd.

68 El Popular, ciudad de México, 21 de febrero de 1898.

69 Ibíd., 19 de febrero de 1898.

70 Ídem.

71 Ídem. 
panorama de incertidumbre y tensión se expresó también el diario The Mexican Herald, en el cual poco a poco se dejó entrever que, a los ojos de los Estados Unidos, la explosión del Maine no había sido un accidente, por lo cual se empezaron a discutir las posibles consecuencias. Por ejemplo, insertaron una nota en la que según un oficial la voladura del buque no se trató de un accidente debido a las estrictas medidas de seguridad por las que se regía el Capitán Sigsbee. ${ }^{72}$

Al mismo tiempo, se publicaron otras informaciones en las que se daba cuenta que algunos abogados habían iniciado una discusión en términos de derecho internacional para discernir si realmente el gobierno de España debería asumir alguna responsabilidad, si se concluía que algún fanático hubiera realizado el ataque contra el Maine; o bien, si la administración española habría incurrido en alguna falta por fortificar con minas sus propios puertos. En este sentido, Robert Lincoln, Secretario de Guerra, declaró lo siguiente: "If is another primary principle that no nation is responsible for accidents. As to the right of a nation to fortify its harbors as it sees fit, there can not be the slightest doubt". ${ }^{73}$ No obstante, en este esfuerzo para evitar el enfrentamiento, otras opiniones insistían que el caso del Maine se había vuelto en un foco infeccioso: "But it was the Maine that went to the bottom of the dirtiest harbor on earth, a cesspool of the accumulated corruption of centuries, making Havana a focus of yellow fever”. Y, por lo tanto, era necesario buscar un remedio más drástico para hacer frente a la fiebre en el Caribe.

\section{CONCLUSIONES}

Este estudio sobre la cobertura de la noticia de la explosión del Maine en la prensa de la ciudad de México permite hacer algunas conclusiones en torno al número, proporción, origen y contenido de las notas periodísticas. En primer lugar, pudimos establecer que el evento del Maine fue ampliamente recogido por los diarios de la ciudad de México, debido tanto a la importancia histórica de Cuba respecto los intereses mexicanos, como a los de los españoles y estadounidenses, los cuales estaban fuertemente representados en el país. Esta cuestión, como señalamos, propició un singular escenario de combate informativo. Los resultados que presentamos indicaron que el evento de la voladura del Maine en la bahía de La Habana fue reportada con un total de 657 notas en 15 periódicos diferentes. Posteriormente, demostramos

72 The Mexican Herald, ciudad de México, 22 de febrero de 1898.
73 Ídem. 
que la cobertura fue desigual en número y en intensidad, de esta manera, anotamos que en este caso los rivales: The Mexican Herald y El Correo Español fueron los periódicos que más informaciones publicaron sobre el Maine entre el 16 y el 22 de febrero de 1898.

En segundo lugar, apuntamos que la inmensa mayoría de las noticias publicadas eran telegramas. De manera que fue posible interrogar a la fuente sobre el lugar y fecha de origen de la información. Esto nos interesó de sobremanera para explorar de dónde y a través de qué canales salieron y circularon las noticias, pues queríamos saber si el origen y el canal informativo repercutieron en el contenido de las noticias, pues a pesar de que el telegrama se presentaba como un medio objetivo e imparcial, su uso no lo era y no lo es. Entre los resultados que presentamos queremos destacar que la mayoría de los periódicos mexicanos publicaron cables cuyo origen remitió a Washington. Le siguieron en orden de preponderancia: La Habana, New York, Madrid y Key West. ¿Cómo era posible que la mayoría de las fuentes de información de la prensa capitalina sobre un evento ocurrido en Cuba se originaron en ciudades norteamericanas? Este hecho se debió a factores tales como, el sobrado interés de parte de los diarios norteamericanos por seguir con detalle el suceso, al sistema telegráfico dominado por Estados Unidos sobre México y el Caribe y, al progresivo cierre y control de las informaciones de parte de las autoridades estadounidenses.

En tercer lugar, establecimos que la cobertura del Maine tuvo tres etapas. La primera, la más numerosa, se dedicó a describir los pormenores de la explosión del buque de guerra. La segunda se caracterizó por la especulación en torno a las causas que provocaron la voladura del Maine; esta etapa fue rica en sospechas y rumores que sembraron las dudas y desconfianzas entre españoles y norteamericanos. La tercera dio cuenta de la escalada diplomática y de la tensión que generaba. Debido a que las instituciones norteamericanas obtuvieron el control tanto de la emisión de las informaciones, como de la interpretación del acontecimiento, se notó que cada vez más se publicaron consideraciones de que el hundimiento del Maine no se había tratado de un "terrible accidente". Finalmente, la idea de que la explosión del acorazado había sido premeditada y, que en consecuencia, se tenía responsabilizar a España a toda costa se esparció a través de la red informativa estadounidense. Así, este relato en el que resonaban los tambores de guerra en el caribe terminó por desembocar en la barbarie que señaló Darío.

\section{FINANCIAMIENTO}

Este proyecto fue financiado por Conacyt (FONCICYT 274861) a través de la convocatoria de Transatlantic Partnership for Social Sciences and Humanities 2016 Digging Into Data Challenge 


\section{FUENTES}

Hemeroteca Digital de la Biblioteca Nacional de España http://hemerotecadigital.bne.es

Hemeroteca Nacional Digital de México. http://www.hndm.unam.mx/

\section{PERIÓDICO}

The New York Journal, New York, 1898.

\section{BIBLIOGRAFÍA}

Barón Fernández, José, La guerra hispano-norteamericana de 1898, Coruña, Ediciós do Castro, 1993.

Bobadilla González, Leticia, “La opinión pública en México frente a la guerra hispano-cubano-americana de 1898. Un estudio histórico-hemerográfico”, tesis de licenciatura en Historia, Universidad Nacional Autónoma de México, 1994.

“1898, Guerra de tinta suelta: la prensa de México durante la intervención norteamericana en Cuba”, en Camacho Navarro, Enrique (coord.), Siete vistas de Cuba: interpretaciones de su independencia, México, Universidad Nacional Autónoma de México, 2001, pp. 127-154.

__ La Revolución cubana en la diplomacia, prensa y clubes de México, 18951898. Tres visiones de una revolución finisecular, México, Secretaría de Relaciones Exteriores, 2001.

Coudart, Laurence, "Periódicos franceses de la ciudad de México: 1837-1911”, en México Francia: Memoria de una sensibilidad común siglos XIX-XIX, tomo I, Ed. Pérez Siller, Javier, México, Centro de Estudios Mexicanos y Centroamericanos, 1998, pp. 103-141.

DOI: https://doi.org/10.4000/books.cemca.4073

, "El espejo estrellado: la caricatura periodística decimonónica”, en Andries, Lise y Suárez de la Torre, Laura (coords.), Impressions du Mexique et de France/Impresiones de México y de Francia, México, Éditions de la Maison des sciences de l'homme/Instituto de Investigaciones Dr. José María Luis Mora, 2009, pp. 255-274.

DOI: https://doi.org/10.4000/books.editionsmsh.9611

Darío, Rubén, “El triunfo de Calibán”, Ed. y notas de Carlos Jáuregui, Revista Iberoamericana, vol. 64, núm. 184, 1998, pp. 451-455.

DOI: https://doi.org/10.5195/REVIBEROAMER.1998.6120

Elizalde, Lydia, El Correo Español: aportes a la prensa periódica en México (18891898), México, Bonilla Artigas Editores/Universidad Autónoma del Estado de Morelos, 2016. 
Fernández Fernández, Iñigo, “Claroscuros de un estadunidense en México: el caso de Paul Hudson (1896-1921)”, Secuencia, núm. 101, 2018, pp. 107-135.

DOI: https://doi.org/10.18234/secuencia.v0i101.1457

Finkel, Jenny Rose, Trond Grenager y Christopher Manning, "Incorporating Non-local Information into Information Extraction Systems by Gibbs Sampling”, Proceedings of the 43rd Annual Meeting on Association for Computational Linguistics, 2005, pp. 363-370. DOI: https://doi.org/10.3115/1219840.1219885

Knudson, Jerry W., “The Mexican Herald: Outpost of Empire, 1895-1915”, Gazette, vol. 63, núm. 5, 2001, pp. 387-398.

DOI: https://doi.org/10.1177/0016549201063005002

Lizardi Pollock, Jorge L., "Imaginar el 98: iconografía mexicana de la guerra hispano-cubano-estadounidense”, Historia Mexicana, vol. 48, núm. 2, 1998, pp. 321-341.

Lombardo García, Irma, De la opinión a la noticia: el surgimiento de los géneros informativos en México, México, Ediciones Kiosco, 2016.

Manning, Christopher D., Prabhakar Raghavan y Hinrich Schutze, "Scoring, Term Weighting, and the Vector Space Model”, en Introduction to Information Retrieval, Nueva York, Cambridge University Press, 2008, pp. 109-133.

Mansouri, Alireza, Lilly Suriani Affendey y Ali Mamat, “Named Entity Recognition Approaches”, International Journal of Computer Science and Network Security, 8.2 2008, pp. 339-344.

Mendoza Vargas, Héctor, "El territorio y la innovación: la red telegráfica mexicana, 1850-1910”, Investigaciones Geográficas. Boletín del Instituto de Geografía, núm. 84, 2014, pp. 96-111. DOI: https://doi.org/10.14350/rig.40011

Muñoz Mata, Laura, “México ante la independencia cubana, 1895-1898. Posición oficial y opinión pública”, Tiempos de América: Revista de historia, cultura y territorio, núms. 3-4, 1999, pp. 19-32.

Pérez Vejo, Tomás, "La guerra hispano-estadounidense del 98 en la prensa mexicana”, Historia Mexicana, vol. 50, núm. 2, 2000, pp. 271-308.

Piccato, Pablo, La tiranía de la opinión. El Honor en la construcción de la esfera pública en México, México, El Colegio de Michoacán/Instituto de Investigaciones José María Luis Mora, 2015.

Rojas, Rafael, "La política mexicana ante la guerra de independencia de Cuba (18951898)”, Historia Mexicana, vol. 45, núm. 4, 1996, pp. 783-805.

, "Retóricas de la raza: intelectuales mexicanos ante la guerra del 98”, Historia Mexicana, vol. 49, núm. 4, 2000, pp. 593-629.

Sánchez Gavito, Indalecio, La Catástrofe del Maine, México, Imprenta de Luis Bustos de Lara, 1898.

Sparck Jones, Karen, "A Statistical Interpretation of Term Specificity and its Application in Retrieval”, Journal of Documentation, vol. 28, núm. 1, 1972, pp. 11-21. DOI: https://doi.org/10.1108/eb026526

Toussaint Alcaraz, Florence, Escenario de la prensa en el Porfiriato, México, Fundación Manuel Buendía/Universidad de Colima, 1989. 